\title{
Alcohol Consumption and Vascular Variability Anomalies (VVAs) and Disorders (VVDs) Detected by C-ABPM
}

\author{
Kuniaki Otsuka $^{1, *}$ and Germaine Cornelissen ${ }^{2}$ \\ ${ }^{I}$ Tokyo Women's Medical University, Medical Center East, Tokyo, Japan \\ ${ }^{2}$ Halberg Chronobiology Center, University of Minnesota, Minneapolis, MN, USA
}

\begin{abstract}
Alterations of the circadian rhythms in blood pressure (BP) and heart rate (HR) have been associated with an increased cardiovascular disease risk. The influence of alcohol consumption on the circadian rhythm characteristics of BP is here examined, and the extent to which such alteration of the circadian BP rhythm contributes to cardiovascular disease risk is assessed.
\end{abstract}

Keywords: Alcohol Consumption, Vascular Variability Anomalies (VVAs), C-ABPM, Relative Risk.

This paper is dedicated to Professor Franz Halberg on the occasion of his $92^{\text {th }}$ birthday, with gratitude for his guidance and friendship. A toast to his innumerable achievements!

\section{INTRODUCTION}

Blood pressure (BP) and heart rate (HR) are highly variable. Their variability includes partly built-in rhythms. Circadian rhythms in particular are generally prominent [1], usually with values lower during sleep/rest, a small increase around mid-sleep [2] followed by a larger increase after awakening, a post-prandial dip accentuating with age [3], and a slow decrease in the evening. A host of other external factors also influence BP and HR, including emotions [4], exercise [5] and other lifestyle features such as smoking [6].

Meals have also been shown to affect BP and HR. Indeed, in a study of 164 newborns fed every 3 hours (except during one timepoint at night) and monitored automatically around the clock during the first week of life, an about 3hour component prominently characterized HR [7]. In another study where babies were fed every 4 hours, a statistically significant spectral peak was found at a frequency of 1 cycle in 4 hours [7]. An increase in HR following meals was demonstrated in a study of clinically healthy nurses, 18-25 years of age, in Tokyo, Japan [8]. They were monitored at 15 -minute intervals for 48 hours, one group of 44 nurses in November 1987 and another group of 50 nurses in June 1988. Time-specified reference limits (chronodesms) computed as $90 \%$ prediction limits showed good reproducibility, notably in terms of the presence of 3 peaks in the morning, around noon, and in the evening, coinciding with meal times [8]. Such meal-associated peaks were not found in similar chronodesms computed from other populations of healthy individuals who did not follow as synchronized a living routine as the Japanese nurses. Figs. (1-3) visualize the circadian patterns as means $+/-1$ standard error for the two groups, documenting the reproducibility of the 3 daytime peaks with the nighttime drop in BP and HR.

*Address correspondence to this author at the Tokyo Women's Medical University, Medical Center East, 2-1-10 Nishiogu, Arakawa-ku, Tokyo, 116-8567 Japan; TellFax: +81-3-3810-9390; E-mail: otsukagm@dnh.twmu.ac.jp
Outcome studies [9-14] have shown that cardiovascular disease risk is increased not only in association with a high $\mathrm{BP}$, but also with alterations of the variability in BP and/or HR $[9,10,15,16]$. In particular, an excessive circadian amplitude of BP (above the upper 95\% prediction limit of clinically healthy peers matched by gender and age), a condition called CHAT (brief for Circadian Hyper-AmplitudeTension) was associated with a large increase in the risk, larger that that of a high BP itself, Fig. (4). Contrary to the linear relation of risk with respect to the BP MESOR (Midline Estimating Statistic Of Rhythm, a rhythm-adjusted mean), the relation of cardiovascular disease risk to the circadian amplitude of BP is nonlinear: risk is increased only after the circadian amplitude of BP exceeds a threshold, Fig. (5).

Herein, we examine whether alcohol affects the circadian rhythm of BP and assess any associated increase in cardiovascular disease risk.

\section{SUBJECTS AND METHODS}

The BP and HR of 297 Japanese non-diabetic patients (145 women and 152 men) were automatically measured every 15 minutes for 48 hours with an ambulatory monitor at the start of the study $[9,10]$. There were 121 MESORnormotensive subjects and 176 treated MESOR-hypertensive patients. Outcomes (cerebral ischemic event, coronary artery disease, nephropathy, and retinopathy), absent at the start of study, were checked every 6 months for 6 years.

Each record was analyzed chronobiologically $[17,18]$. Estimates of the MESOR and of the circadian amplitude and acrophase were interpreted in the light of reference values from clinically healthy peers matched by gender and age. Screening for VVDs identified patients with MESORHypertension (MH) and CHAT, among others. The relative risk [19] associated with $\mathrm{MH}$ and CHAT was determined and compared with that of other known risk factors assessed concomitantly. These included obesity, high cholesterol, gender, family history, smoking, age, as well as alcohol consumption. The relative risk of CHAT was further 
Circadian pattern of systolic blood pressure (SBP) of two groups of Japanese nurses characterized by 3 daytime peaks coinciding with meals

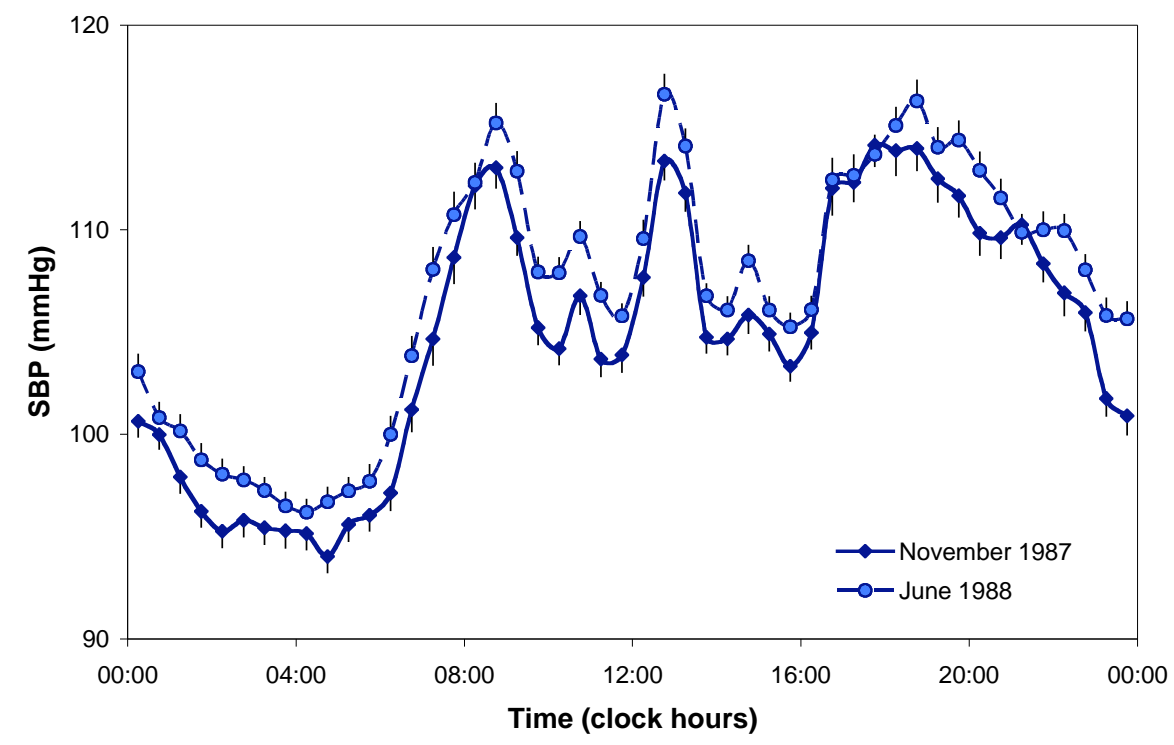

Fig. (1). Circadian pattern of systolic blood pressure computed for two groups of Japanese nurses monitored in November 1987 and June 1988 who followed a synchronized living routine. The presence of three peaks in the morning, around noon, and in the evening coincide with meal times. (C) Halberg (with permission).
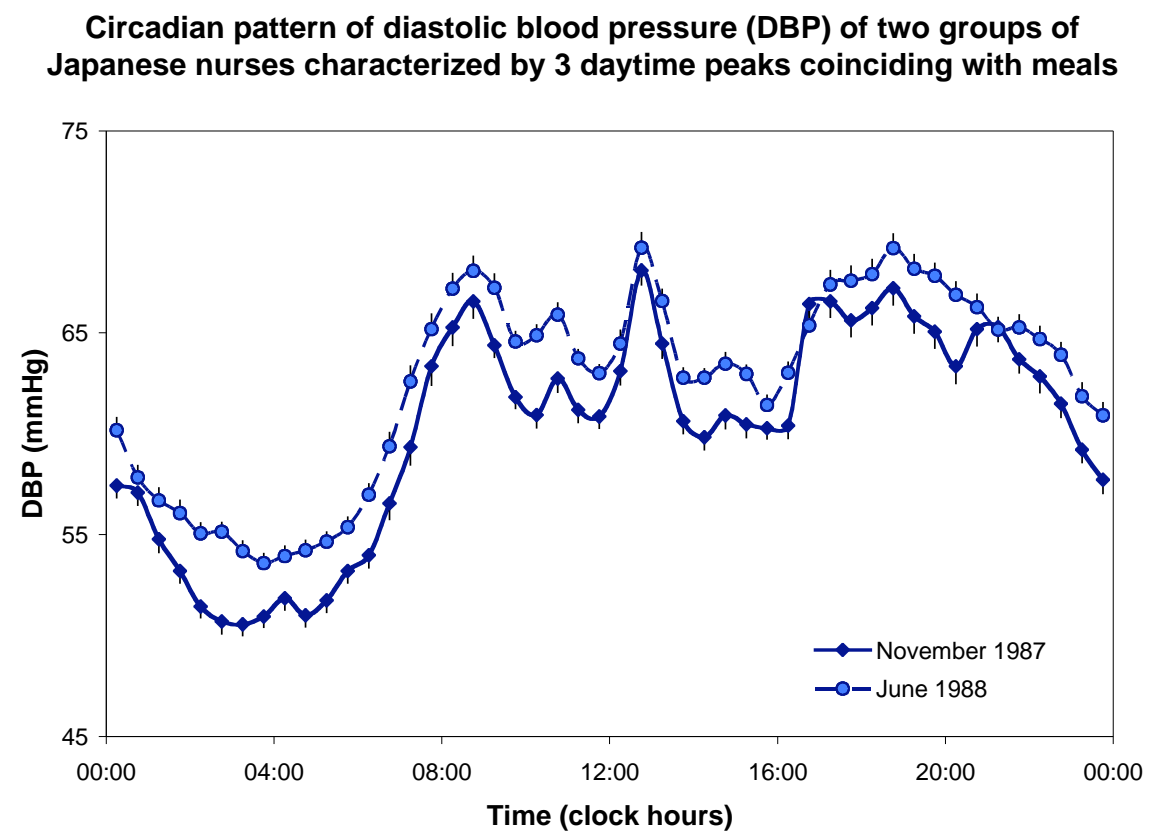

Fig. (2). Circadian pattern of diastolic blood pressure computed for two groups of Japanese nurses monitored in November 1987 and June 1988 who followed a synchronized living routine. The presence of three peaks in the morning, around noon, and in the evening coincide with meal times. (c) Halberg (with permission).

assessed in patients who checked negative for any one of the other risk factors considered each separately.

Previously, relative risk had been assessed separately for each kind of outcome [9, 10, 20]. Notably in the case of cerebral ischemic events and nephropathy, CHAT was found to represent, at least numerically, a risk higher than that of MESOR-Hypertension. As compared to obesity, high cholesterol, male gender, a positive family history (FH) of high BP and/or related cardiovascular disease, smoking, being older than 60 years of age, and MESOR-Hypertension, CHAT carried a higher risk of cerebral ischemic events and nephropathy. When considering subpopulations not presenting with one of the other given risk factors, the risk associated with CHAT remained statistically significant, indicating that the risk of cerebral ischemic events and nephropathy was raised in the presence of CHAT, irrespective of the effect of the other risk factor being tested concomitantly [20]. 


\section{Circadian pattern of heart rate (HR) of two groups of Japanese nurses characterized by 3 daytime peaks coinciding with meals}

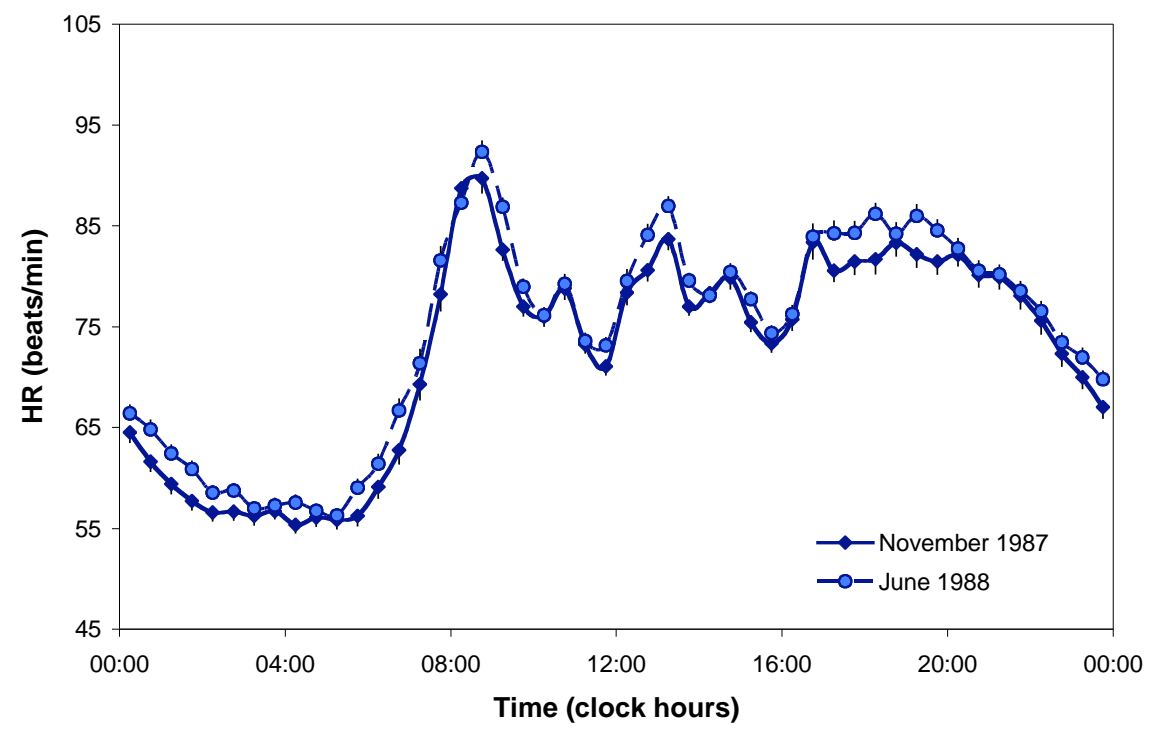

Fig. (3). Circadian pattern of heart rate computed for two groups of Japanese nurses monitored in November 1987 and June 1988 who followed a synchronized living routine. The presence of three peaks in the morning, around noon, and in the evening coincide with meal times. (C) Halberg (with permission).

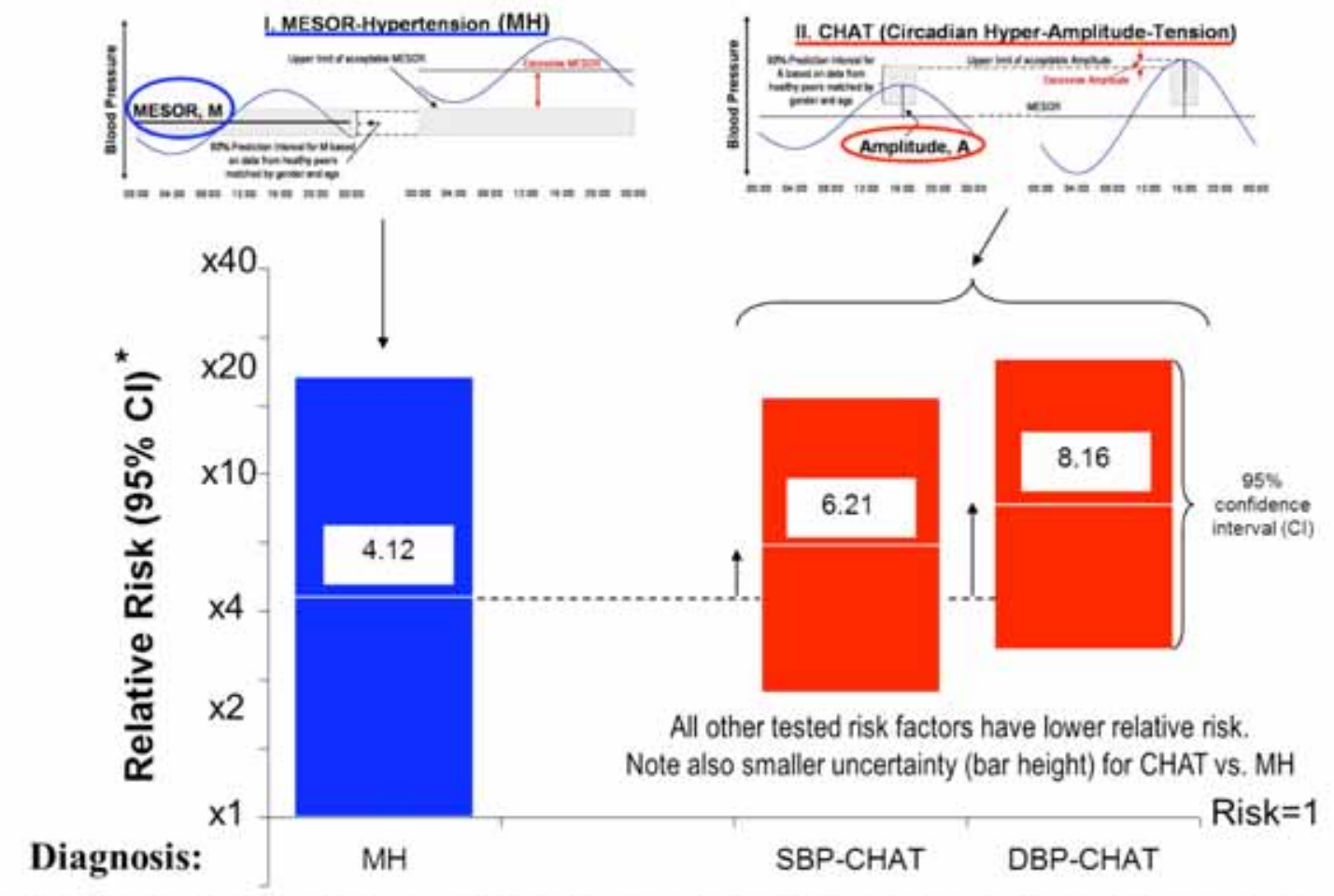

'Risk of Cerebral Ischemic Event ( $\mathrm{N}=297)$. Results are in keeping with independent outcome study on 1179 untreated patients, using the left ventricular mass index as proxy.

Fig. (4). In the clinic population of 297 Japanese patients, MESOR-Hypertension increased the risk of a cerebral ischemic event within 6 years by $312 \%(R R=4.12)$. The increase in risk is statistically significant, as evidenced by the non-overlap of equal risk $(R R=1)$ by the $95 \%$ confidence interval. By comparison, systolic and diastolic CHAT are associated with an even larger risk of great statistical significance. (C) Halberg (with permission).

Herein, relative risk is assessed in relation to all outcomes considered jointly. After 6 years, 39 patients developed coronary artery disease, cerebral ischemia, nephropathy and/or retinopathy. 


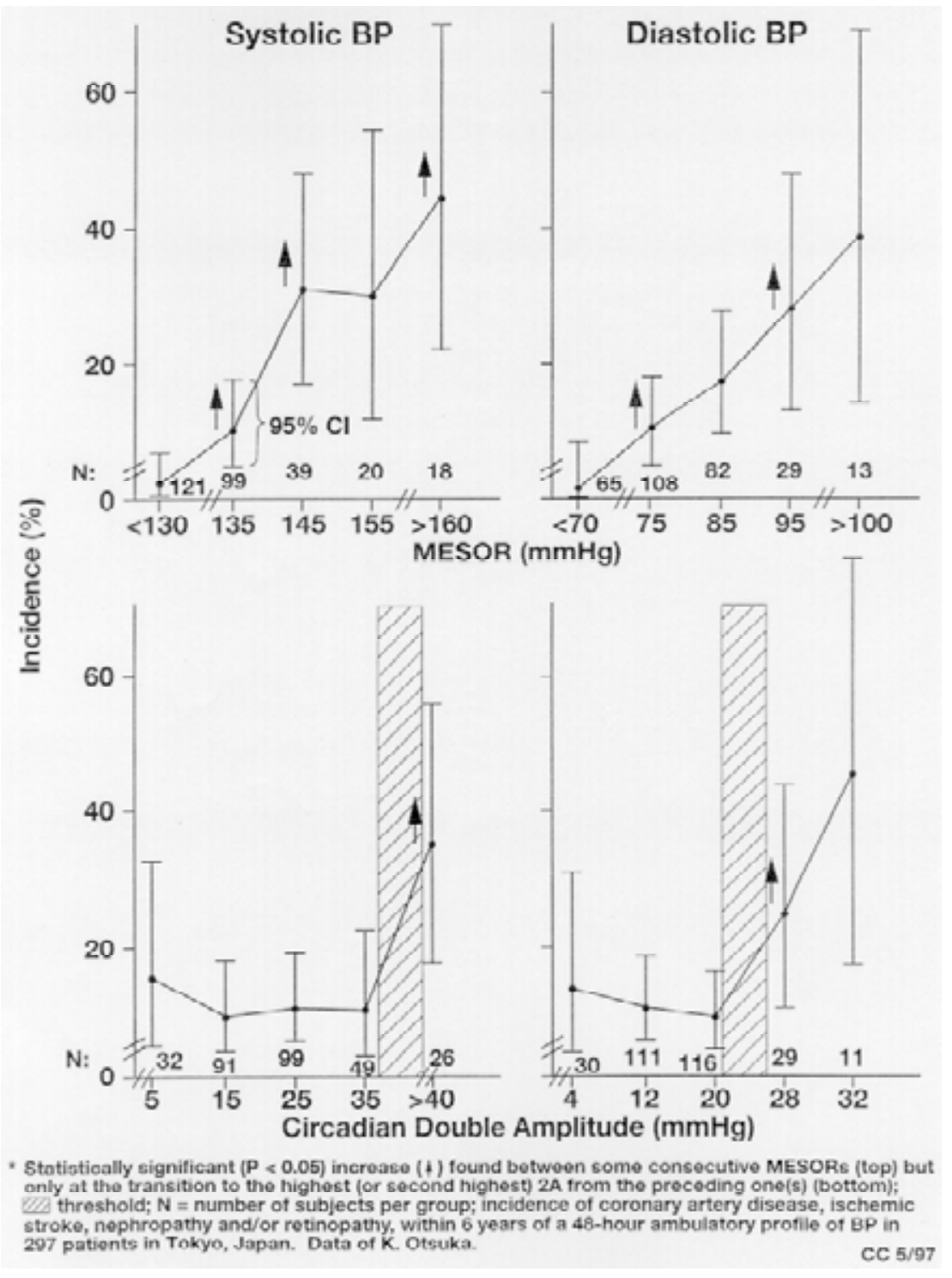

Fig. (5). In the clinic population of 297 Japanese patients, the incidence of adverse outcomes within 6 years is linearly related to the MESOR of systolic and diastolic BP: the higher the MESOR, the larger the risk. By contrast, the circadian (double) amplitude of BP has a nonlinear relation to risk: for a wide range of amplitudes, there is no increase in risk, but risk increases sharply and statistically significantly once the circadian amplitude of BP exceeds a threshold. (c) Halberg (with permission).

\section{RESULTS}

Among the 297 patients, 195 were drinkers and 102 nondrinkers. Adverse outcomes after 6 years affected $18.6 \%$ of drinkers as compared to $10.3 \%$ of non-drinkers $\left(\chi^{2}=4.114\right.$, $\mathrm{P}=0.043)$. The relative risk (RR) of alcohol consumption with its $95 \%$ confidence interval (CI) is 1.82 [1.02, 3.25]. As seen in Fig. (6), alcohol consumption is associated with a statistically significant increase in cardiovascular disease risk, whereas in the population investigated, obesity, high cholesterol, male gender, and a positive family history of high BP and/or related cardiovascular disease are not. Smoking is associated with an even higher RR of 2.33 [1.31, 4.13] $\left(\chi^{2}=8.425, \mathrm{P}=0.004\right)$, as is age above 60 years with a $\mathrm{RR}$ of $3.64[2.08,6.36]\left(\chi^{2}=21.145, \mathrm{P}<0.001\right)$, and $\mathrm{MH}$ with a RR of $8.25[2.60,26.18]\left(\chi^{2}=20.310, P<0.001\right)$. Systolic and diastolic CHAT also have a relative risk statistically significantly higher than $1(\mathrm{P}<0.001)$. Whereas it is less than that of $\mathrm{MH}$, their smaller CIs indicate a higher specificity [21].

Similar results are observed for the subpopulation of nondrinkers, as shown in Fig. (7). No statistically significant increase in cardiovascular disease risk is found in association with obesity, high cholesterol, male gender or a positive FH. Smoking has a RR of 2.27 [0.90, 5.69] reaching borderline statistical significance $(\mathrm{P}=0.085)$. Age $(\mathrm{RR}=6.63, \mathrm{P}<0.001)$ and $\mathrm{MH}(\mathrm{RR}=7.56, \mathrm{P}=0.001)$ remain the largest risk factors, while diastolic CHAT remains a significant risk factor ( $\mathrm{RR}=3.23, \mathrm{P}=0.019)$, systolic CHAT reaching borderline statistical significance $(\mathrm{RR}=2.62, \mathrm{P}=0.059)$. In the smaller subpopulation of drinkers, only $\mathrm{MH}$ and CHAT are found to significantly increase cardiovascular disease risk $(\mathrm{MH}$ : $\mathrm{RR}=8.23, \mathrm{P}=0.007$; S-CHAT: RR=3.38, $\mathrm{P}=0.003$; D-CHAT: $\mathrm{RR}=4.83$, $\mathrm{P}<0.001$ ), Fig. (8). Again, the lesser RR of CHAT 


\title{
Extent of increase in cardiovascular disease risk, based on incidence of adverse outcomes, in the presence of various factors investigated
}

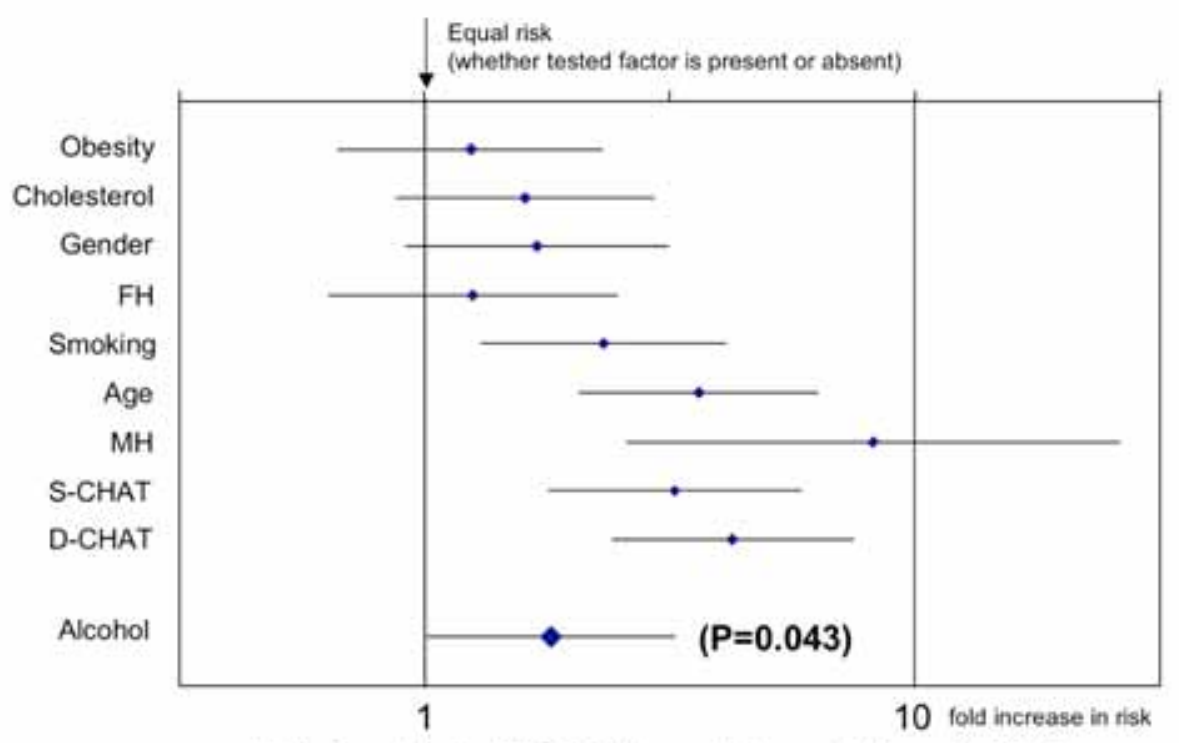

Relative Risk, RR [ 95\% confidence interval, $\mathrm{Cl}$ ] *

\begin{abstract}
- Horizontal bar $(95 \% \mathrm{Cl})$ overlapping RR=1 indicates lack of statistical significance: tested risk factor is not significantly associated with an increase in cardiovascular disease risk, based on adverse outcomes.

FH: Family History; MH: MESOR-Hypertension; CHAT: Circadian Hyper-Amplitude-Tension (S, Systolic; D, Diastolic)
\end{abstract}

Fig. (6). Overall cardiovascular disease risk (diamonds) is statistically significantly increased in association with alcohol consumption, as evidenced by the non-overlap of equal risk $(\mathrm{RR}=1)$ by the $95 \%$ confidence interval of the relative risk (horizontal bars). Apart from age, MESOR-Hypertension, and CHAT, only smoking is also associated with a statistically significant increase in cardiovascular disease risk in the clinic population of 297 Japanese patients. (C) Halberg (with permission).

\section{Extent of increase in cardiovascular disease risk, based on incidence of adverse outcomes, in the presence of various factors investigated}

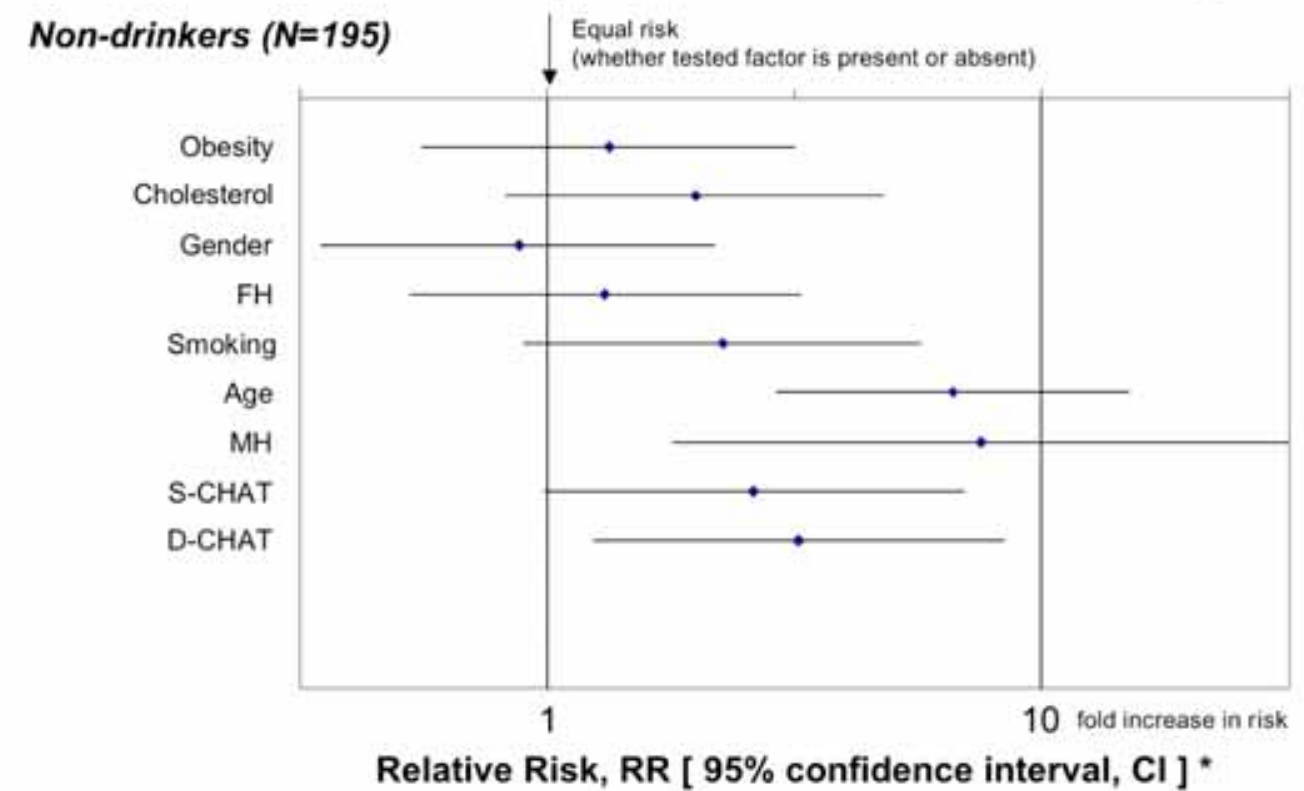

- Horizontal bar $(95 \% \mathrm{Cl})$ overlapping RR=1 indicates lack of statistical significance: tested risk factor is not significantly associated with an increase in cardiovascular disease risk, based on adverse outcomes.

FH: Family History; MH: MESOR-Hypertension; CHAT; Circadian Hyper-Amplitude-Tension (S, Systolic; D, Diastolic)

Fig. (7). Among the 195 non-drinkers, age, MESOR-Hypertension and CHAT remain statistically significantly associated with an increase in overall cardiovascular disease risk, while smoking reaches borderline statistical significance. () Halberg (with permission). 


\section{Extent of increase in cardiovascular disease risk, based on incidence of adverse outcomes, in the presence of various factors investigated}

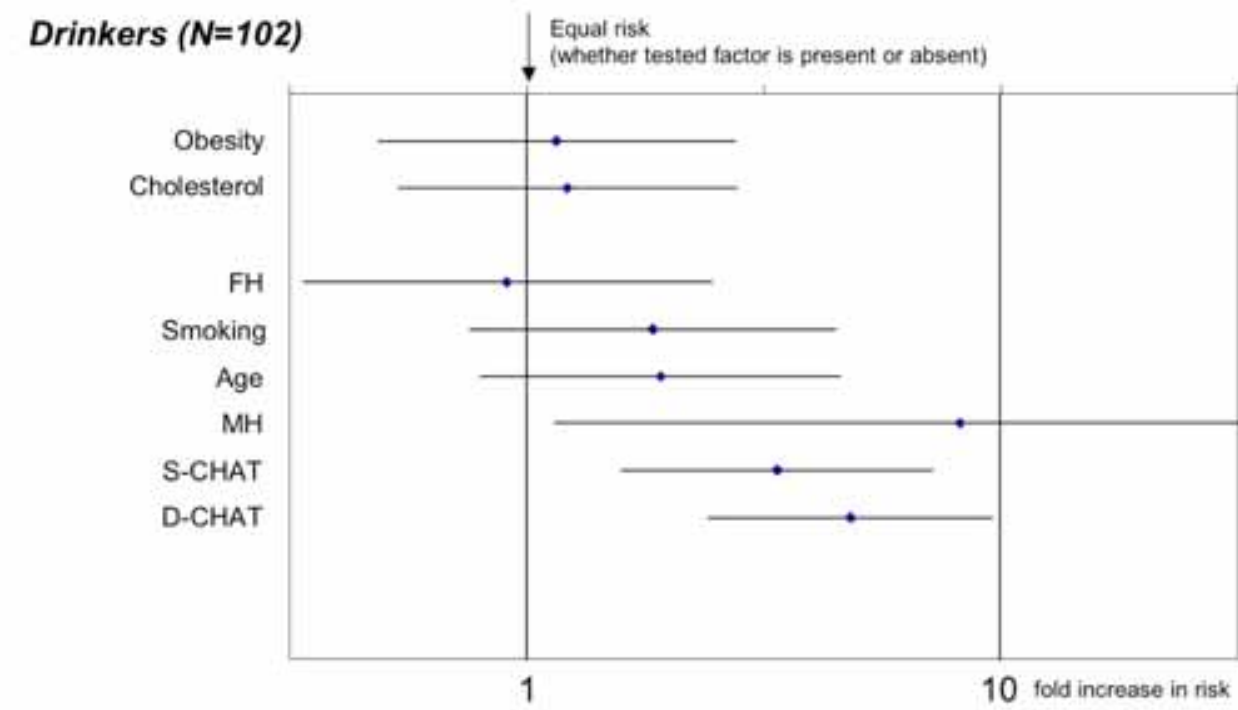

Relative Risk, RR [ 95\% confidence interval, $\mathrm{Cl}$ ] *

- Horizontal bar $(95 \% \mathrm{Cl})$ overlapping RR=1 indicates lack of statistical significance: tested risk factor is not significantly associated with an increase in cardiovascular disease risk, based on adverse cutcomes. FH: Family History; MH: MESOR-Hypertension; CHAT; Circadian Hyper-Amplitude-Tension (S, Systolic; D, Diastolic)

Fig. (8). In the smaller subpopulation of 102 drinkers, only MESOR-Hypertension and CHAT are associated with a statistically significant increase in overall cardiovascular disease risk. (C) Halberg (with permission).

Alcohol Effect on Circadian Blood Pressure Characteristics *

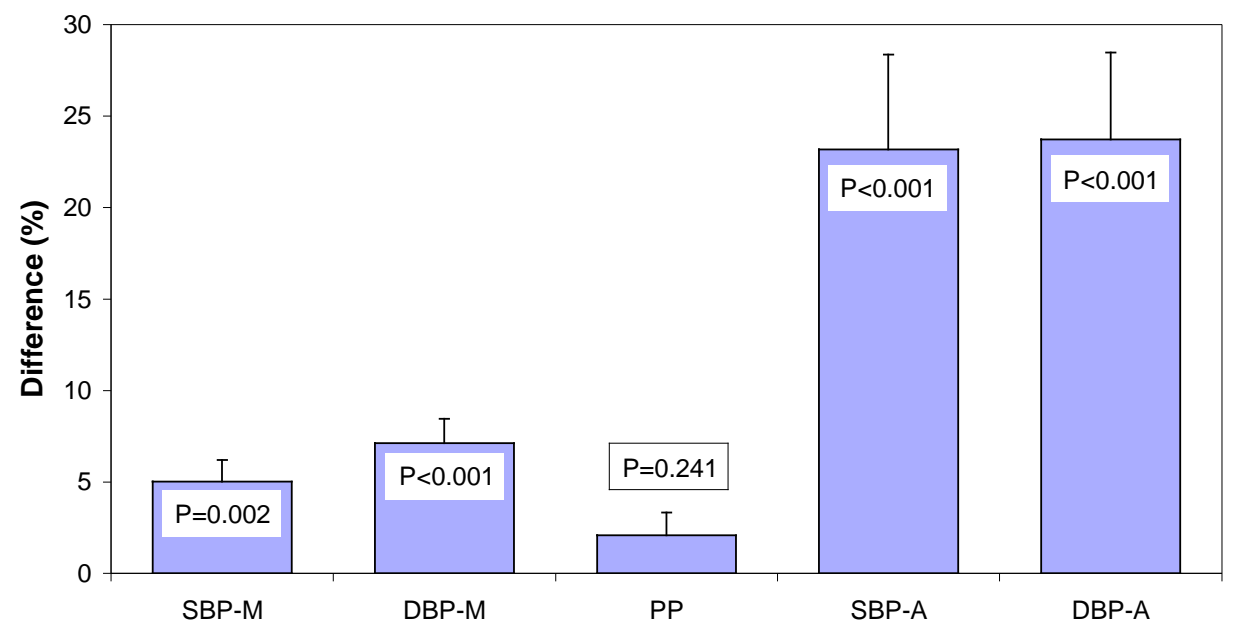

* SBP: Systolic Blood Pressure; DBP: Diastolic Blood Pressure; PP: Pulse Pressure; M: MESOR; A: 24-hour Amplitude Difference between average from 102 patients drinking alcohol and average from 195 patients not drinking alcohol, used as reference, shown with standard error; P-values from Student t test assuming equal variance.

Fig. (9). Alcohol consumption is associated with a small statistically significant increase in the BP MESOR, with a much larger statistically significant increase in the circadian amplitude of BP, but no effect on pulse pressure. (C) Halberg (with permission).

as compared to $\mathrm{MH}$ may be viewed in the light of its smaller CI indicative of higher specificity [21].

A comparison of circadian characteristics between drinkers and non-drinkers shows that alcohol consumption is associated with a statistically significant increase in both the MESOR and in the circadian amplitude of systolic and diastolic BP, while it does not affect pulse pressure, Fig. (9).
The BP MESOR, however, is only slightly increased by 5 to 7\% (SBP: 135.5 vs. $129.1 \mathrm{mmHg}$; DBP: 81.6 vs. 76.2 $\mathrm{mmHg}$ ). By contrast, alcohol consumption has a much larger influence on the circadian amplitude of BP, which is increased by over $20 \%$ (SBP: 27.1 vs. $22.0 \mathrm{mmHg}$; DBP: 19.1 vs. $15.4 \mathrm{mmHg}$ ). It is thus conceivable that in patients with a strong circadian variation at the outset, alcohol 


\section{Extent of increase in cardiovascular disease risk, based on incidence of adverse outcomes, in the presence of various factors investigated}

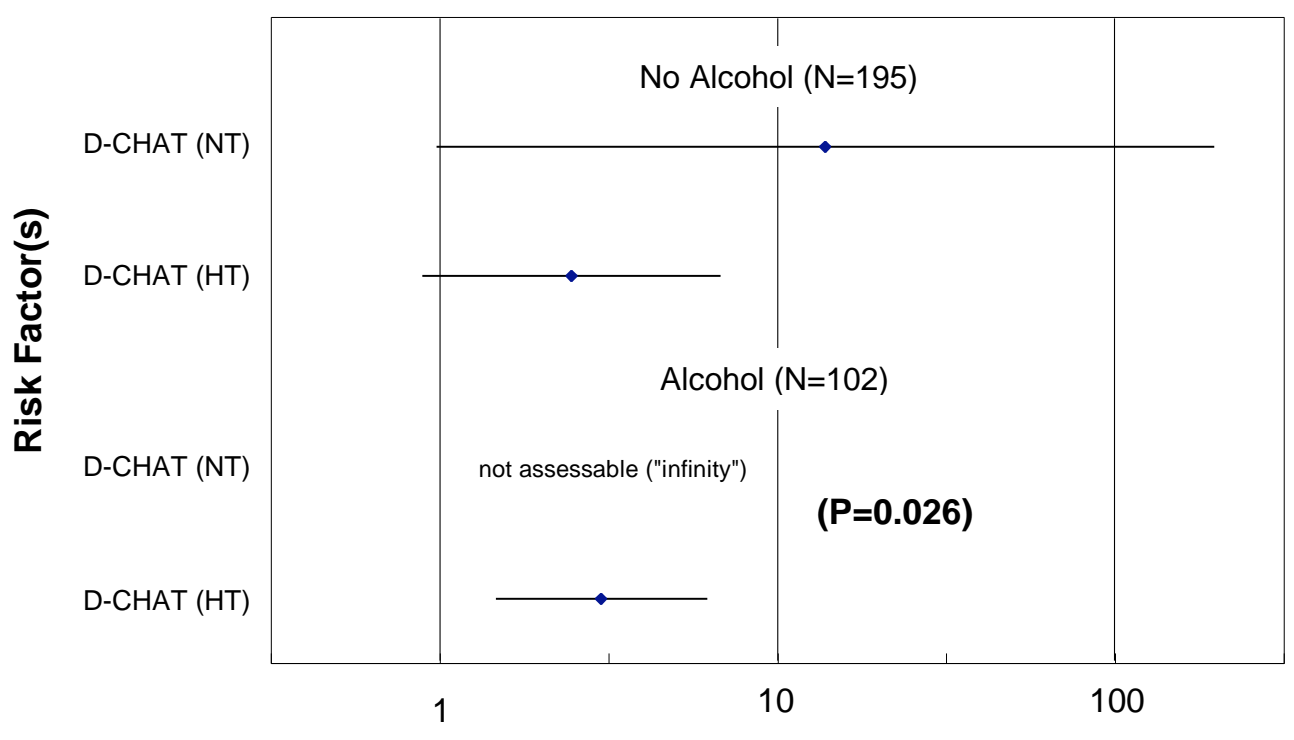

Relative Risk, RR [ 95\% confidence interval, $\mathrm{Cl}$ ] *

* Horizontal bar $(95 \% \mathrm{Cl})$ overlapping $\mathrm{RR}=1$ indicates lack of statistical significance: tested risk factor is not significantly associated with an increase in cardiovascular disease risk, based on adverse outcomes.

D-CHAT: Diastolic Circadian Hyper-Amplitude-Tension; NT \& HT: MESOR-Normotensive \& -Hypertensive Patients.

Fig. (10). In both normotensive subjects and in MESOR-hypertensive patients, diastolic CHAT is associated with a large increase in overall cardiovascular disease risk among drinkers as well as non-drinkers. (C) Halberg (with permission).

consumption may bring about CHAT, thereby increasing their cardiovascular disease risk. Results in Figs. (6-8) document that despite the effect of alcohol consumption on the circadian amplitude of BP, CHAT remains an independent risk factor, remaining statistically significant in the subpopulation of non-drinkers.

The risk of CHAT is also independent of MH, as shown in Fig. (10). In MESOR-normotensive subjects (NT), diastolic CHAT is associated with a RR of 13.83 [0.98, 194.8] $\left(\chi^{2}=6.090, \mathrm{P}=0.014\right)$ among non-drinkers. Among drinkers, the only subject with diastolic CHAT suffered a morbid event, whereas none of the subjects with an acceptable circadian amplitude of diastolic BP had an event (Fisher's exact test: $\mathrm{P}=0.026$ ). In (treated) MESORhypertensive patients, diastolic CHAT is associated with a $\mathrm{RR}$ of $2.45[0.89,6.72]\left(\chi^{2}=2.584, \mathrm{P}=0.108\right)$ among nondrinkers, and with a RR of $3.00[1.47,6.14]\left(\chi^{2}=7.179\right.$, $\mathrm{P}=0.007)$ among drinkers. The fact that numerically, cardiovascular disease risk is higher among drinkers than among non-drinkers is in keeping with the increase in the circadian amplitude of BP associated with alcohol consumption. The much larger RR observed in normotensive subjects by comparison with MESOR-hypertensive patients may be accounted for by the earlier documentation that CHAT may be a condition preceding the onset of MESORhypertension observed both in the laboratory [22] and in the clinic [23, 24].

\section{DISCUSSION AND CONCLUSION}

In another study [25], the BP of 7 clinically healthy Japanese volunteers was studied in a cross-over design. For 5 days, the subjects consumed either $40 \mathrm{~g}$ of alcohol by day or fruit juice, the two spans on alcohol and juice being separated by a 1-week washout. In the absence of a difference in BP MESOR, alcohol consumption was clearly associated with a statistically significant increase in the circadian amplitude of BP [25], in keeping with our results herein.

Similar results were observed in a case study of a 70-year old Japanese man who drank 7-8 180ml-bottles of sake per day [26]. Advised to reduce his alcohol intake gradually, he first cut his consumption by $50 \%$ for 2 days, than by $65 \%$ for another 2 days, before restraining from any alcohol consumption. Whereas the BP MESORs of systolic and diastolic BP remained between 160.7/93.6 and 164.9/95.0 $\mathrm{mmHg}$, their circadian amplitudes decreased progressively and statistically significantly from $26.0 / 10.9$ to $7.9 / 4.0$ $\mathrm{mmHg}$ [26].

Alcohol consumption was also related to an increase in the circadian amplitude of BP in a 68-year old man with benign prostatic hypertrophy and hypertension, regardless of medication [27]. The self-study was prompted by the diagnosis of CHAT. Between September and November 1999, he changed his drinking habits (consuming between 0 and 8 ounces of liquor each evening) and the time of Hytrin intake, monitoring his $\mathrm{BP}$ and $\mathrm{HR}$ around the clock. In September, decreasing alcohol intake from 4 to 0 ounces brought about no decrease in BP MESOR but a decrease in the circadian amplitude (systolic BP: from 24.1 to 13.5 $\mathrm{mmHg}$; diastolic BP: from 19.9 to $12.4 \mathrm{mmHg}$; $\mathrm{P}<0.001$ ), eliminating the existing CHAT [27]. In November, a dose response of the circadian amplitude of $\mathrm{BP}$ was observed 
when alcohol consumption was reduced from 8 to 4 and then to 2 ounces of liquor each evening, the amplitude dropping from $13.7 / 10.9$ to $8.8 / 8.0$ and $7.9 / 7.8 \mathrm{mmHg}$ (systolic/ diastolic BP) [27].

Our results indicate that alcohol consumption is primarily associated with an increase in the circadian amplitude of BP, with no major change in the BP MESOR. Heavy alcohol drinking is reportedly associated with an increased incidence of morbid cardiovascular events, thought to be mediated by changes in BP, yet there is no consensus on the effect of alcohol intake on BP, likely because conventional trials rely mostly on casual single measurements, ignoring the BP dynamics. An increase of the circadian amplitude of BP above an acceptable threshold, bringing about CHAT, may be a testable mechanism possibly underlying the increase in the incidence of morbid events among drinkers.

\section{AREAS AWAITING EXPLORATION BY SCHOLARS IN NUTRITION}

While the foregoing discussion revolves around evidence related to the topic of this journal, the scope of our Tokyo/Minnesota cooperation is much broader [28-32]. It touches on chronomics in two ways, also pertinent to future nutritional investigation, namely the cosmos and the glocality of its effects. In terms of time, to think globally and act locally means that time series are analyzed as a whole (globally) as well as in systematically varied consecutive shorter sections (locally) to resolve the overall time structure, keeping in mind that cycles may change their characteristics (frequency, amplitude, phase) as a function of time. Nutritionists will gain if the scope of their endeavors is extended not only to assessing rhythms but also trends and other features of chaos [33]. The senior author introduced glocality in a spatial context [34] and extends it to the study of time varying effects from the cosmos [35; see also 28-32], while concerns in Minnesota tried to explore sampling requirements, notably for nutritionists interested in a premetabolic syndrome [36].

\section{CONFLICT OF INTEREST}

Declared none.

\section{ACKNOWLEGMENT}

Declared none.

\section{REFERENCES}

[1] Reinberg A, Ghata J, Halberg F, Gervais P, Abulker C, Dupont J, Gaudeau C. Rythmes circadiens du pouls, de la pression artérielle, des excrétions urinaires en 17-hydroxycorticostéroïdes, catécholamines et potassium chez l'homme adulte sain, actif et au repos. Ann Endocrinol (Paris) 1970; 31: 277-87.

[2] Halberg E, Halberg F, Shankaraiah K. Plexo-serial linear-nonlinear rhythmometry of blood pressure, pulse and motor activity by a couple in their sixties. Chronobiologia 1981; 8: 351-66.

[3] Cornelissen G, Haus E, Halberg F. Chronobiologic blood pressure assessment from womb to tomb. In: Touitou Y, Haus E, Eds. Biological rhythms in clinical and laboratory medicine. Berlin: Springer-Verlag 1992; pp. 428-52.

[4] Halberg F, Cornelissen G, Halberg E, et al. Chronobiology of human blood pressure. Medtronic Continuing Medical Education Seminars. $4^{\text {th }}$ ed. Minneapolis: Medtronic Inc. 1988; p. 242.

[5] Levine H, Saltzman W, Yankaskas J, Halberg F. Circadian statedependent effect of exercise upon blood pressure in clinically healthy men. Chronobiologia 1977; 4: 129-30.
[6] Scarpelli PT, Livi R, Scarpelli L, et al. Cigarette-smoking effects on circadian rhythm parameters of blood pressure. Proc. 2nd Ann. IEEE Symp. on Computer-Based Medical Systems, Minneapolis, June 26-27, 1989. Washington DC: Computer Society Press 1989; pp. 267-272.

[7] Cornelissen G, Siegelova J, Halberg F. Blood pressure and heart rate dynamics during pregnancy and early extra-uterine life: Methodology for a chrononeonatology. In: Halberg F, Kenner T, Fiser B, Eds. Proceedings, Symposium: The importance of chronobiology in diagnosing and therapy of internal diseases. Faculty of Medicine, Masaryk University, Brno, Czech Republic, January 10-13, 2002. Brno: Masaryk University 2002; pp. 58-96.

[8] Otsuka K, Cornelissen G, Watanabe H, Halberg F. Reproducibility of circadian patterns in blood pressure and heart rate of groupsynchronized healthy women and circannual effects. In: Halberg F, Watanabe H, Eds. Proc. workshop on computer methods on chronobiology and chronomedicine, Tokyo, Sept. 13, 1990. Tokyo: Medical Review 1992; pp. 185-201.

[9] Otsuka K, Cornelissen G, Halberg F. Predictive value of blood pressure dipping and swinging with regard to vascular disease risk. Clin Drug Invest 1996; 11: 20-31.

[10] Otsuka K, Cornelissen G, Halberg F, Oehlert G. Excessive circadian amplitude of blood pressure increases risk of ischemic stroke and nephropathy. J Med Eng Technol 1997; 21: 23-30.

[11] Chen ChH, Cornelissen G, Siegelova J, Halberg F. Does overswinging provide an early warning of cardiovascular disease risk when non-dipping may fail? A meta-analysis of 2039 cases. Scripta medica (Brno) 2001; 74: 75-80.

[12] Cornelissen G, Chen ChH, Siegelova J, Halberg F. Vascular disease risk syndromes affecting both MESOR-normotensives and MESOR-hypertensives: a meta-analysis of 2039 cases. Scripta medica (Brno) 2001; 74: 81-6.

[13] Müller-Bohn T, Cornelissen G, Halhuber M, Schwartzkopff O, Halberg F. CHAT und Schlaganfall. Deutsche Apotheker Zeitung 2002; 142: 366-70.

[14] Müller-Bohn T, Cornelissen G, Halberg F, Halhuber M, Delea CS. Blood pressure variability gauged by circadian overswing (CHAT) and lifespan; 2010 June 3; Time Series (not spotcheck) EvidenceBased Holistic Approach to Health, 1st International Workshop of the TsimTsoum Institute, Krakow, Poland 2010; pp. 22-3.

[15] Halberg F, Cornelissen G, Otsuka K, et al. Extended consensus on means and need to detect vascular variability disorders (VVDs) and vascular variability syndromes (VVSs). Leibniz-Online Nr. 5, 2009; Available at: (http://www2.hu-berlin.de/leibniz-sozietaet/ journal/archiv_5_09.html). p. 35 .

[16] Cornelissen G, Halberg F, Otsuka K, Singh RB. Separate cardiovascular disease risks: circadian hyper-amplitude-tension (CHAT) and an elevated pulse pressure. World Heart J 2008; 1: 223-32.

[17] Cornelissen G, Otsuka K, Halberg F. Blood pressure and heart rate chronome mapping: a complement to the human genome initiative. In: Otsuka K, Cornelissen G, Halberg F, Eds. Chronocardiology and chronomedicine: humans in time and cosmos. Tokyo: Life Science Publishing 1993; pp. 16-48.

[18] Halberg F, Cornelissen G, Wall D, et al. Engineering and governmental challenge: 7-day/24-hour chronobiologic blood pressure and heart rate screening. Part II. Biomed Instrum Techn 2002; 36(3): 183-97.

[19] Agresti A. Categorical data analysis. New York: John Wiley \& Sons 1990.

[20] Halberg F, Cornelissen G, International Womb-to-Tomb Chronome Initiative Group: Resolution from a meeting of the International Society for Research on Civilization Diseases and the Environment (New SIRMCE Confederation), Brussels, Belgium, March 17-18, 1995: Fairy tale or reality? Medtronic Chronobiology Seminar \#8, April 1995, p. 12. 18 figures. Available at: http://www.msi.umn.edu/ halberg/

[21] Cornelissen G, Halberg F, Bakken EE, et al. 100 or 30 years after Janeway or Bartter, Healthwatch helps avoid "flying blind". Biomed Pharmacother 2004; 58(Suppl 1): S69-86.

[22] Halberg J, Halberg E, Hayes DK, et al. Schedule shifts, life quality and quantity modeled by murine blood pressure elevation and arthropod lifespan. Int J Chronobiol 1980; 7: 17-64.

[23] Kumagai Y, Shiga T, Sunaga K, Cornelissen G, Ebihara A, Halberg F. Usefulness of circadian amplitude of blood pressure in predicting hypertensive cardiac involvement. Chronobiologia 1992; 19: 43-58. 
[24] Watanabe Y, Cornelissen G, Halberg F, et al. Incidence pattern and treatment of a clinical entity, overswinging or circadian hyperamplitudetension (CHAT). Scripta medica (Brno) 1997; 70: 245-61.

[25] Kumagai Y, Shiga T, Sunaga K, et al. Repeated alcohol intake changes circadian rhythm of ambulatory blood pressure. Chronobiologia 1993; 20: 77-85.

[26] Watanabe Y, Cornelissen G, Otsuka K. Ohkawa S, Siegelova J, Halberg F. Effect of alcohol intake and treatment with calcium antagonist on blood pressure and heart rate assessed by ambulatory monitoring. Scripta medica (Brno) 2001; 74: 103-6.

[27] Sonkowsky R, Cornelissen G, Fink H, Homolka P, Siegelova J, Halberg F. Day-to-day variability prompts seven-day and 24-hour blood pressure profiles. Scripta medica (Brno) 2002; 75: 267-74.

[28] Otsuka K, Ed. Biomed Pharmacother. Netherlands: Elsevier Science 2001; 55(Suppl 1): pp. 7s-190s.

[29] Otsuka K, Ed. Biomed Pharmacother. Netherlands: Elsevier Science 2002; 56 (Suppl 2): pp. 231s-382s.

[30] Otsuka K, Ed. Biomed Pharmacother. Netherlands: Elsevier Science 2003; 57 (Suppl 1): pp. 1s-198s.
[31] Otsuka K, Ed. Biomed Pharmacother. Netherlands: Elsevier Science 2004; 58 (Suppl 1): pp. S1-S188.

[32] Otsuka K. (Ed.) Biomed \& Pharmacother. Netherlands: Elsevier Science 2005; 59 (Suppl 1): pp. S1-S261.

[33] Otsuka K, Cornelissen G, Halberg F. Circadian rhythmic fractal scaling of heart rate variability in health and coronary artery disease. Clin Cardiol 1997; 20: 631-8.

[34] Otsuka K, Cornelissen G, Norboo T, Takasugi E, Halberg F. Chronomics and "glocal" (combined global and local) assessment of human life. Prog Theor Phys 2008; 173: 134-52.

[35] Otsuka K, Ichimaru Y, Cornelissen G, et al. Dynamic analysis of heart rate variability from 7-day Holter recordings associated with geomagnetic activity in subarctic area. Comput Cardiol 2000; 27: 453-6.

[36] Halberg F, Cegielski N, Cornelissen G, et al. Timing nutrition makes the difference concerning body weight and survival: Sampling requirements for a 7-day/24-hour circadian endocrine stress-strain test for nutritionists interested in a premetabolic syndrome. Proceedings, 15th Congress of Clinical Nutrition; 2010 Sept 19-22; El Sakhna, Egypt 2010. pp. 26-34. 